\title{
Adenovirus Capsid-Based Anti-Cocaine Vaccine Prevents Cocaine from Binding to the Nonhuman Primate CNS Dopamine Transporter
}

\author{
Anat Maoz ${ }^{1,2,7}$, Martin J Hicks ${ }^{3,7}$, Shankar Vallabhjosula ${ }^{1,2}$, Michael Synan ${ }^{2}$, Paresh J Kothari', \\ Jonathan P Dyke ${ }^{2}$, Douglas J Ballon ${ }^{2}$, Stephen M Kaminsky ${ }^{3}$, Bishnu P De ${ }^{3}$, Jonathan B Rosenberg ${ }^{3}$, \\ Diana Martinez ${ }^{4}$, George F Koob ${ }^{5}$, Kim D Janda ${ }^{6}$ and Ronald G Crystal*,3 \\ 'Division of Nuclear Medicine and Molecular Imaging, Weill Cornell Medical College, New York, NY, USA; ${ }^{2}$ Citigroup Biomedical Imaging Center, \\ Department of Radiology, Weill Cornell Medical College, New York, NY, USA; ${ }^{3}$ Department of Genetic Medicine, Weill Cornell Medical College, \\ New York, NY, USA; ${ }^{4}$ Division of Substance Abuse, Department of Psychiatry, Columbia University, New York, NY, USA; ${ }^{5}$ Committee on the \\ Neurobiology of Addictive Disorders, The Skaggs Institute for Chemical Biology, and Worm Institute of Research and Medicine, The Scripps \\ Research Institute, La Jolla, CA, USA; ${ }^{6}$ The Departments of Chemistry and Immunology, The Skaggs Institute for Chemical Biology, and Worm \\ Institute of Research and Medicine, The Scripps Research Institute, La Jolla, CA, USA
}

\begin{abstract}
Cocaine addiction is a major problem for which there is no approved pharmacotherapy. We have developed a vaccine to cocaine (dAd5GNE), based on the cocaine analog GNE linked to the capsid proteins of a serotype 5 adenovirus, designed to evoke anti-cocaine antibodies that sequester cocaine in the blood, preventing access to the CNS. To assess the efficacy of dAd5GNE in a large animal model, positron emission tomography (PET) and the radiotracer [ ' ' C]PE2I were used to measure cocaine occupancy of the dopamine transporter (DAT) in nonhuman primates. Repeat administration of dAd5GNE induced high anti-cocaine titers. Before vaccination, cocaine displaced PE2I from DAT in the caudate and putamen, resulting in $62 \pm 4 \%$ cocaine occupancy. In contrast, dAd5GNEvaccinated animals showed reduced cocaine occupancy such that when anti-cocaine titers were $>4 \times 10^{5}$, the cocaine occupancy was reduced to levels of $<20 \%$, significantly below the $47 \%$ threshold required to evoke the subjective 'high' reported in humans. Neuropsychopharmacology (2013) 38, 2170-2178; doi:10.1038/npp.2013.1 I4; published online I2 June 2013
\end{abstract}

Keywords: cocaine; vaccine; dopamine transporter (DAT); PET imaging; addiction

\section{INTRODUCTION}

With an estimated 1.4 million cocaine users in the United States, cocaine addiction is a major problem for which there are no FDA-approved therapies (Dept. of Health and Human Services 2011). The cocaine 'high' is initiated by cocaine-mediated accumulation of dopamine in the ventral striatum, caudate, and putamen of the basal ganglia (DiChiara et al 2004; Koob and Volkow 2010; Volkow et al 1997a; Volkow et al 1997b). Dopamine is synthesized in the presynaptic neuron and is stored in intracellular vesicles (Anderson et al 1998; Koob and Volkow 2010). Following release of dopamine from the presynaptic neuron into the synaptic cleft, dopamine binds to dopamine

*Correspondence: Dr RG Crystal, Department of Genetic Medicine, Weill Cornell Medical College, I 300 York Avenue, Box I64, New York, NY 10065, USA, Tel: +I 646962 4363, Fax: + I 646962 0220, E-mail: geneticmedicine@med.cornell.edu

${ }^{7}$ These authors contributed equally to this work.

Received 30 January 2013; revised 25 April 2013; accepted 26 April 2013; accepted article preview online 10 May 2013 receptors on the postsynaptic neuron, and to the dopamine transporter (DAT) for reuptake by the presynaptic neuron (Haile et al 2012b; Howell and Kimmel 2008; Kahlig and Galli 2003). Cocaine binds to the DAT and inhibits dopamine reuptake, resulting in dopamine accumulation in the synaptic cleft of the transmitting neuron. This prolongs and amplifies postsynaptic dopamine signaling at the dopamine receptors, resulting in rewarding effects (Haile et al 2012b; Nader and Czoty 2005; Volkow et al 1997b). In humans, at least $47 \%$ of the DAT must be occupied by cocaine to evoke the perceived rewarding effects or 'high' (Volkow et al 1997a).

The strategy of an anti-cocaine vaccine is to prevent cocaine access to the brain, and hence, to prevent the ability of cocaine to reach the DAT in the caudate and the putamen. Two approaches, passive and active immunization, have been used to develop anti-cocaine immunotherapies. The small size and lipid solubility of addictive drugs represent a great challenge for therapies that seek to block the rapid passage across the blood-brain barrier and ultimately restrict access to cognate receptors. A therapeutic approach that engages the addictive drug before crossing the blood-brain barrier, before it stimulates the drug 
reinforcement and reward pathways, would have the advantage of blocking the effect by specifically targeting the drug itself and not impacting normal downstream CNS signaling pathways.

Passive immunotherapies for the treatment of cocaine addiction make use of monoclonal antibodies directed toward the cocaine molecule (Brimijoin et al 2013; Carroll et al 2012; Norman et al 2007; Ramakrishnan et al 2012). Current strategies, at this time tested only in experimental animals, either administer large amounts of purified anticocaine monoclonal antibodies (to use as an antidote to treat overdose) (Treweek and Janda 2012) or for longer duration treatment, gene therapy to the liver of the gene sequence of the anti-cocaine monoclonal antibody to induce persistent expression of the monoclonal antibody (Rosenberg et al 2012).

Active vaccines against cocaine are comprised of a cocaine analog coupled to an immunogenic protein. The TA-CD vaccine, succinylated norcocaine linked to cholera toxin B subunit, was effective in experimental animals, and in humans demonstrated some efficacy for those individuals in whom it evoked high anti-cocaine titers (Haney et al 2010; Martell et al 2009; Shen et al 2012). With the goal of blocking access of cocaine to the CNS to prevent DAT occupancy levels that induce cocaine's psychotropic effects, we have developed an anti-cocaine vaccine (dAd5GNE) based on a cocaine analog covalently coupled to the capsid proteins of a disrupted serotype 5 human adenovirus (Hicks et al 2011; Wee et al 2012). Studies in mice and rats have shown that dAd5GNE prevents cocaine-induced hyperactivity and addiction-related behavior in these species (Koob et al 2011; Hicks et al 2011; Wee et al 2012).

In general, vaccine studies in rodents are not sufficient to predict efficacy in humans, whereas nonhuman primates (NHP), due to similar physiology and genetics, are considered informative (Herodin et al 2005). For the cocaine vaccine, efficacy is measured by a phenotype that depends upon cocaine-DAT binding at levels above a threshold. Because rodents and primates metabolize cocaine and the DAT radiotracers differently, measures of these compounds in the NHP brain better model humans and thus are more relevant for translation to clinical study (Lindsey et al 2004; Nader and Czoty 2008; Seki et al 2010; Shetty et al 2007; Volkow et al 1997a; Ward and Smith 2004; Wilcox et al 2002). Furthermore, the large brain of the NHP imaged with positron emission tomography (PET) technology also provides the high resolution for quantitative imaging of the putamen and caudate, areas of the CNS directly relevant to cocaine addiction (Halldin et al 2003; Volkow et al 1997a).

The goal of the present study was to use PET imaging to directly assess the capacity of dAd5GNE to block cocaine access to the DAT transporter in the brain of NHP and to determine whether this blockade persists with repeated cocaine administrations over time. To accomplish this, we used the PET imaging radiotracer $\left[{ }^{11} \mathrm{C}\right]$ PE2I, a high-affinity ligand specific for DAT (Dolle et al 2000; Emond et al 2008; Halldin et al 2003), to evaluate the efficacy of dAd5GNE to repeatedly prevent cocaine from crossing the blood-brain barrier and block DAT function of NHP.

\section{METHODS}

\section{dAd5GNE Vaccine}

The source of the adenovirus capsid proteins for the dAd5GNE vaccine was Ad5 $\beta$ gal, a recombinant Ela ${ }^{-}$, partial $\mathrm{E} 1 \mathrm{~b}^{-}$, and the $\mathrm{E}^{-}$serotype 5 Ad vector with $\beta$-galactosidase in the expression cassette (Hicks et al 2011; Rosenfeld et al 1992; Wee et al 2012). The Ad5 $\beta$ gal vector was disrupted in $0.5 \%$ sodium dodecyl sulfate at $56^{\circ} \mathrm{C}$ for $45 \mathrm{~s}$. The cocaine hapten GNE $(0.3 \mathrm{mg})$ was activated overnight at $4{ }^{\circ} \mathrm{C}$ after the addition of $7.2 \mu$ l charging solution (2.4 mg of 1-ethyl-3-(3-dimethylaminopropyl) carbodiimide hydrochloride and $2 \mathrm{mg}$ of $\mathrm{N}$-hydroxysulfosuccinimide in $4 \mu \mathrm{H} \mathrm{H}_{2} \mathrm{O}$ and $40 \mu \mathrm{l}$ dimethylformamide) (Hicks et al 2011; Wee et al 2012). The conjugation of the disrupted Ad5 $\beta$ gal vector $(200 \mu \mathrm{g})$ with the charged GNE (67 $\mu \mathrm{g} ; 300: 1$ GNE to Ad capsomere molar ratio) was carried out by overnight incubation at $4{ }^{\circ} \mathrm{C}$ in phosphatebuffered saline (PBS, pH 7.4). The amount of Ad vector proteins was quantified using the bicinchoninic acid assay (Pierce Biotechnology, Rockford, IL).

\section{Study Design}

The study included five female Rhesus macaques (Macaca mulatta), age $5.1 \pm 0.6$ years. Four were vaccinated with the dAd5GNE vaccine and one was used as a non-vaccinated control. After an initial PET scan (see below), four animals were vaccinated by intramuscular injection to the quadriceps with $100 \mu \mathrm{g}$ of dAd5GNE in a $0.5-\mathrm{ml}$ volume, formulated in $20 \%$ Adjuplex (Advanced BioAdjuvants, Omaha, NE), an adjuvant made with a purified lecithin and carbomer homopolymer. The vaccine was administered at 0,3 , and 5 weeks for all four animals, and subsequently, as required to maintain high titer for PET scan. Before and multiple times after initial vaccine administration, venous blood was collected to assess anti-cocaine antibodies. The blood was allowed to clot $\left(30 \mathrm{~min}, 23^{\circ} \mathrm{C}\right)$, and centrifuged at $10000 \mathrm{~g}$ for $20 \mathrm{~min}$. The isolated serum was stored at $-20{ }^{\circ} \mathrm{C}$. PET scans with $\left[{ }^{11} \mathrm{C}\right]$ PE2I were carried out before and 2-5 times after the initial vaccination over a period of 12 months (see Supplementary Table S1).

\section{dAd5GNE Evoked Anti-Cocaine Antibody Titers}

To quantify anti-cocaine titers following vaccination, wells of flat-bottomed 96-well EIA/RIA plates (Corning, New York, NY) were coated with $100 \mu \mathrm{l}$ of $1 \mathrm{mg} / \mathrm{ml}$ of the cocaine hapten GNE (Hicks et al 2011; Wee et al 2012) conjugated to bovine serum albumin (BSA, ratio of $1: 2$ ) in bicarbonate buffer, $\mathrm{pH} 9.4$ overnight at $4{ }^{\circ} \mathrm{C}$ (the conjugation was as described above but BSA was substituted for dAd5). The plates were washed with $0.05 \%$ Tween 20 in PBS (PBS-Tween) and blocked with 5\% dry milk in PBS for $30 \mathrm{~min}, 23^{\circ} \mathrm{C}$. Twofold serial dilutions of serum were added to each well and incubated for $90 \mathrm{~min}, 23^{\circ} \mathrm{C}$. The plates were washed four times with PBS-Tween. Diluted horseradish peroxidase-conjugated goat anti-monkey IgG (Santa Cruz Biotechnology, Santa Cruz, CA), $100 \mu 1$ of $1: 2000$ in $1 \%$ dry milk in PBS, was added to each well and incubated for $90 \mathrm{~min}, 23^{\circ} \mathrm{C}$. The plates were washed four times. Peroxidase substrate $(100 \mu \mathrm{l} /$ well; Bio-Rad, Hercules, CA) was 
added and incubated for $15 \mathrm{~min}, 23^{\circ} \mathrm{C}$. The peroxidase reaction was stopped with addition of $2 \%$ oxalic acid $(100 \mu \mathrm{l} /$ well). Absorbance was measured at $415 \mathrm{~nm}$. Anticocaine antibody titers were calculated by interpolation of the $\log (\mathrm{OD})-\log$ (dilution) with a cutoff value equal to twofold the absorbance of background.

\section{Synthesis of $\left[{ }^{11} \mathrm{C}\right] \mathrm{PE} 2 \mathrm{I}$}

$\left[{ }^{11} \mathrm{C}\right] \mathrm{PE} 2 \mathrm{I}$ was synthesized by reacting the precursor (1R,2S,3S,5S)-8-azabicyclo[3.2.1] octane-2-carboxylic acid, 8-[(2E)-3-iodo-2-propenyl]-3-(4-methylphenyl) (PE2I acid) in acetone with ${ }^{11} \mathrm{C}$-labeled methyl ester of trifluoromethansulfonic acid $\left({ }^{11} \mathrm{C}\right.$-methyl triflate) at $50{ }^{\circ} \mathrm{C}$ for $5 \mathrm{~min}$ (Dolle et al 2000). Synthesis was initiated with $0.5 \mathrm{mg}$ precursor (PE2I acid) dissolved in $500 \mu \mathrm{l}$ acetone and $3 \mu \mathrm{l} 2 \mathrm{M}$ sodium hydroxide added $\sim 3 \mathrm{~min}$ before the release of ${ }^{11} \mathrm{C}$-methyl triflate. Upon completion of the ${ }^{11} \mathrm{C}$-methyl triflate collection, the reaction mixture was heated for $5 \mathrm{~min}$ at $50^{\circ} \mathrm{C}$ followed by reaction quenching with $1 \mathrm{ml}$ mobile phase. The reaction mixture was loaded onto a $7.8 \mathrm{~mm} \times 300 \mathrm{~mm}$ Waters' $\mu$ Bondapak C-18 column (Waters Co, Milford, $\mathrm{MA}$ ) and column eluted with $0.01 \mathrm{M}$ phosphoric acid: acetonitrile gradient at $6 \mathrm{ml} / \mathrm{min}$. The fraction containing $\left[{ }^{11} \mathrm{C}\right] \mathrm{PE} 2 \mathrm{I}$ was collected into $50 \mathrm{ml}$ water. $\left[{ }^{11} \mathrm{C}\right] \mathrm{PE} 2 \mathrm{I}$ was trapped on Waters' C-18 sep-pak cartridge (Waters Co) and subsequently formulated with $7 \%$ ethanolic saline solution followed by sterile filtration using a $0.22-\mu \mathrm{m}$ membrane filter. The synthesis was accomplished in $40.8 \pm 2.7 \mathrm{~min}$. The radiochemical yield was $40.1 \pm 5.8 \%$ (decay corrected) with the chemical and radiochemical purities in excess of $90 \%$. The average specific activity (SA) of $\left[{ }^{11} \mathrm{C}\right] \mathrm{PE} 2 \mathrm{I}$ at the end of synthesis was $13.8 \pm 6.1 \mathrm{Ci} / \mu \mathrm{mol}$. In each study, there was no significant difference in the SA of $\left[{ }^{11} \mathrm{C}\right]$ PE2I according to time of administration (first administration, $9.1 \pm 4.3$ vs second administration, $7.9 \pm 3.6 \mathrm{Ci} / \mu \mathrm{mol}, P=0.3)$.

\section{PET and MRI Imaging}

PET imaging studies were performed following intravenous administration of $\left[{ }^{11} \mathrm{C}\right]$ PE2I $(5 \mathrm{mCi})$. At each session, PET imaging was carried out before and after cocaine challenge $(1 \mathrm{mg} / \mathrm{kg})$. Cocaine was injected over a period of $30 \mathrm{~s}$ via an intravenous port located either in the saphenous vein (leg) or the cephalic vein (arm). During the vaccination regimen, PET studies were repeated for each animal 2-5 times over a period of 12 months (see Supplementary Table S1).

PET scans were performed using a microPET scanner (Siemens/CTI Concorde Focus 220). Data was acquired in list mode format for $90 \mathrm{~min}$. Following acquisition, a ${ }^{57} \mathrm{Co}$ point source was used for attenuation correction. Histograms were created consisting of 28 time frames; 4 of $15 \mathrm{~s}$, 4 of $30 \mathrm{~s}, 7$ of $60 \mathrm{~s}, 10$ of $300 \mathrm{~s}$, and 3 of $600 \mathrm{~s}$. Images were reconstructed using ordered subset expectation maximization two-dimensional. Each series was composed of 95 slices (field-of-view) with $128 \times 128$ matrix yielding a $1.9 \mathrm{~mm} \times 1.9 \mathrm{~mm} \times 0.8 \mathrm{~mm}$ voxel size.

Magnetic resonance imaging (MRI) was performed on each NHP using a 3.0-Tesla Siemens TIM Trio scanner (Siemens, Malvern, PA) with a single loop surface coil placed on the head. An axial 3D $\mathrm{T}_{2}$-weighted spin-echo sequence used a $18 \mathrm{~cm} \times 18 \mathrm{~cm}$ field-of-view, $1.0 \mathrm{~mm}$ slice thickness, 72 slices, $256 \times 256$ in-plane matrix, and an echo train length of 259 , yielding $0.7 \mathrm{~mm} \times 0.7 \mathrm{~mm} \times 1.0 \mathrm{~mm}$ voxel resolution. A $3200 \mathrm{~ms}$ pulse sequence repetition time and an effective echo time of $454 \mathrm{~ms}$ was used with four averages, resulting in a scan time of $6 \mathrm{~min}$. To identify CNS structures, PET scans were co-registered to their corresponding MRI scans using FSL/Flirt (FMRIB's linear image registration tool, version 4.0, FMRIB Image Analysis Group, Oxford, UK). The cerebellum was identified as a reference region (Ciliax et al 1999; Seki et al 2010). Anatomical localization of the regions of interest, caudate and putamen, and the reference region were identified on coronal MRI images and used for PET quantification (see coronal images for illustration of tracing of the regions of interest, Supplementary Figure S1).

\section{Quantitative Analysis}

To quantify the DAT binding potential (BP) from in vivo PET studies, the specific binding of the radioligand $\left[{ }^{11} \mathrm{C}\right] \mathrm{PE} 2 \mathrm{I}$ to the target receptor (DAT) was measured using the four-parameter reference tissue model (Hume et al 1992; Lammertsma et al 1996). This model requires two time-activity curves: one from DAT receptor-rich region (in this study, the caudate and putamen) and one from a reference region devoid of receptors (in this study, the cerebellum). The model assumes that the distribution volume of the non-displaceable compartment (free and nonspecifically bound tracer) is the same for the tissue of interest (caudate and putamen) and the reference tissue (cerebellum). Using the model, the ratio at equilibrium of specifically bound radioligand to non-displaceable radioligand (sum of free and nonspecifically bound radioligand in tissue) can be determined, and is defined as the $\mathrm{BP}_{\mathrm{ND}}$ (Innis et al 2007). The $\left[{ }^{11} \mathrm{C}\right]$ PE2I radioligand was administered at a tracer dose (see above) to avoid perturbation of the receptor-ligand system (Innis et al 2007). Quantification was done using PMod software (PMOD version 3.1; PMOD Technologies, Zurich, Switzerland).

To determine the cocaine occupancy, two consecutive $\left[{ }^{11} \mathrm{C}\right]$ PE2I PET scans in the absence or presence of cocaine were performed. In the first scan only $\left[{ }^{11} \mathrm{C}\right] \mathrm{PE} 2 \mathrm{I}$ was administered, whereas in the second scan cocaine $(1.0 \mathrm{mg} / \mathrm{kg})$ was administered and immediately followed by $\left[{ }^{11} \mathrm{C}\right]$ PE2I. The two separate scans allowed for calculation of cocaine DAT occupancy based on the displacement of $\left[{ }^{11} \mathrm{C}\right]$ PE2I by cocaine. The change in $\left[{ }^{11} \mathrm{C}\right]$ PE2I BP, $\triangle \mathrm{BP}_{\mathrm{ND}}$, was calculated from the difference between the $\mathrm{BP}$ (calculated from the PET scan) in the absence of cocaine $\mathrm{BP}_{\mathrm{ND}}$ (no cocaine) and the $\mathrm{BP}$ in the presence of cocaine, $\mathrm{BP}_{\mathrm{ND}}$ (cocaine). Cocaine DAT occupancy was calculated from the difference in $\left[{ }^{11} \mathrm{C}\right]$ PE2I BP $(\triangle \mathrm{BP})$ and normalized to $\left[{ }^{11} \mathrm{C}\right] \mathrm{PE} 2 \mathrm{I} \mathrm{BP}_{\mathrm{ND}}$ (no cocaine). The percentage of occupancy of DAT by cocaine (\% occupancy) is defined by the equation (Innis et al 2007):

$$
\% \text { occupancy }=\frac{\mathrm{BP}_{\mathrm{ND}}(\text { no cocaine })-\mathrm{BP}_{\mathrm{ND}}(\text { cocaine })}{\mathrm{BP}_{\mathrm{ND}}(\text { no cocaine })} \times 100
$$




\section{Statistics}

Data (antibody titer, BP, and cocaine occupancy) are expressed as mean $\pm \mathrm{SE}$, specific activity is expressed as mean $\pm \mathrm{SD}$. A paired repeated measures analysis of variance accounting for within-subject variability was performed before and after vaccination. Additionally, comparisons between vaccinated and non-vaccinated groups were conducted by unpaired two-sample $t$-test (Table 1). The nonvaccinated group included all PET studies from experimental NHP before vaccination and the one non-vaccinated control, and the PET studies from vaccinated animals were categorized into two groups: (1) all NHP after vaccination and (2) those only with titers $>4 \times 10^{5}$. The Pearson correlation was used to calculate the correlation coefficient between anti-cocaine antibody titer and cocaine occupancy (\%). PET studies were also sub-categorized according to titer; no titers, titers $<4 \times 10^{5}$, and titers $>4 \times 10^{5}$, and comparisons between groups were conducted by unpaired two-sample $t$-test. Statistical analysis was done using Matlab (Mathworks, Natick, MA).

\section{RESULTS}

Administration of the dAd5GNE vaccine evoked high titers of anti-cocaine antibody by 7 weeks after initial immunization (Figure 1a-d). Repeat administration of dA5GNE boosted the anti-cocaine antibody titer during the 50-week study. No anti-cocaine antibody titers were seen in the control NHP. On the average, after the prime and second boost for the four NHP, the titers were $4.9 \pm 0.4 \times 10^{5}$. As we observed in mice and rats (Hicks et al 2011; Wee et al 2012), maintenance of high titer required re-administration of the vaccine.

To evaluate the capacity for cocaine occupancy of DAT, the affinity of the $\left[{ }^{11} \mathrm{C}\right]$ PE2I radiotracer for DAT was measured by determination of the BP in the absence of cocaine according to reference tissue modeling as described in Methods (Sasaki et al 2012; Seki et al 2010). PET imaging of the brain of naive NHPs (both control and NHPs before vaccination) showed that $\left[{ }^{11} \mathrm{C}\right] \mathrm{PE} 2 \mathrm{I}$ bound to the highdensity DAT region of the striatum, with a high BP in the caudate $(8.3 \pm 0.3, n=8)$ and the putamen $(8.7 \pm 0.4, n=8$; Figure $2 \mathrm{a}$ left images, Figure $2 \mathrm{~b}-\mathrm{e}$ top left images, and Table 1). Vaccinated NHPs had a similarly high BP of $\left[{ }^{11} \mathrm{C}\right] \mathrm{PE} 2 \mathrm{I}$ to the DAT in the caudate $(9.1 \pm 0.7, n=12)$ and the putamen $(9.1 \pm 0.7, n=12$; Figure $2 \mathrm{~b}-\mathrm{e}$, bottom left images and Table $1 ; P=0.3$ ). There was no difference in $\mathrm{BPs}$ in the absence of cocaine between vaccinated and

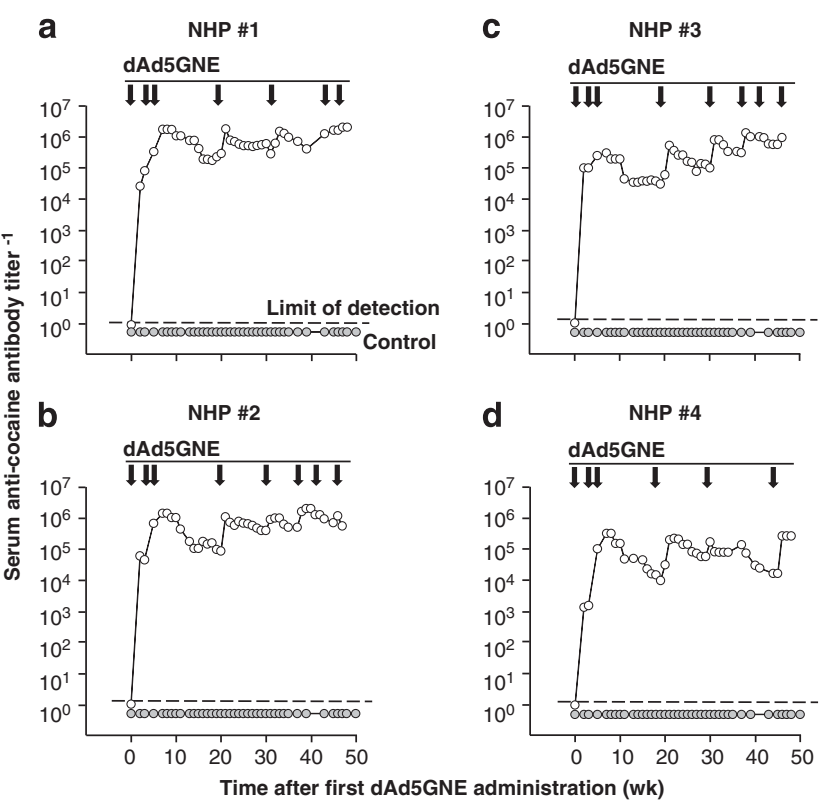

Figure I Anti-cocaine antibody titers over time in dAd5GNE-vaccinated nonhuman primates (NHP). (a-d) NHP \#I-4. NHP \#5 was the nonvaccinated control; the data for the control is shown in each panel. Antibody titer levels $\left(\log _{10}\right)$ were assessed by ELISA over a 50 -week period. dAd5GNE vaccine administration is indicated by arrows for each NHP.

Table I [ [ C]PE2I Binding Potential and \% Cocaine Occupancy ${ }^{\mathrm{a}}$

\begin{tabular}{|c|c|c|c|c|c|c|c|c|c|}
\hline \multirow[t]{2}{*}{ Category $^{b}$} & \multicolumn{6}{|c|}{ [' 'C]PE2I binding potential } & \multirow{2}{*}{$\begin{array}{l}\% \text { Cocaine } \\
\text { occupancy } \\
\text { caudate }\end{array}$} & \multirow{2}{*}{$\begin{array}{c}\% \text { Cocaine } \\
\text { occupancy } \\
\text { putamen }\end{array}$} & \multirow{2}{*}{$\begin{array}{c}\text { \% Cocaine } \\
\text { occupancy } \\
\text { caudate }+ \text { putamen }\end{array}$} \\
\hline & $\begin{array}{l}\text { Caudate } \\
\text { no cocaine }\end{array}$ & $\begin{array}{l}\text { Putamen } \\
\text { no cocaine }\end{array}$ & $\begin{array}{l}\text { Caudate }+ \\
\text { cocaine }\end{array}$ & $\begin{array}{l}\text { Putamen }+ \\
\text { cocaine }\end{array}$ & $\begin{array}{l}\text { Caudate } \\
\text { (change) }\end{array}$ & $\begin{array}{l}\text { Putamen } \\
\text { (change) }\end{array}$ & & & \\
\hline Non-vaccinated & $8.3 \pm 0.3$ & $8.7 \pm 0.3$ & $3.2 \pm 0.4$ & $3.2 \pm 0.4$ & $5.2 \pm 0.4$ & $5.5 \pm 0.4$ & $62.3 \pm 4.5$ & $62.7 \pm 3.9$ & $62.5 \pm 4.1$ \\
\hline Vaccinated & $9.1 \pm 0.7$ & $9.1 \pm 0.7$ & $6.3 \pm 0.5$ & $6.3 \pm 0.5$ & $2.8 \pm 0.6$ & $2.8 \pm 0.7$ & $28.3 \pm 4.9$ & $27.0 \pm 6.1$ & $27.6 \pm 5.4$ \\
\hline $\begin{array}{l}\text { Non-vaccinated } \\
\text { vs vaccinated } \\
P \text {-value }\end{array}$ & 0.21 & 0.35 & $<8.4 \times 10^{-5}$ & $<1.7 \times 10^{-4}$ & $<5.6 \times 10^{-3}$ & $<6.8 \times 10^{-3}$ & $<7.1 \times 10^{-5}$ & $<2.0 \times 10^{-4}$ & $<4.4 \times 10^{-8}$ \\
\hline $\begin{array}{l}\text { Non-vaccinated } \\
\text { vs titers } \\
>4 \times 10^{5} \\
\text { P-value }\end{array}$ & 0.42 & 0.26 & $<1.6 \times 10^{-4}$ & $<7.7 \times 10^{-5}$ & $<6.8 \times 10^{-7}$ & $<6.7 \times 10^{-7}$ & $<3.0 \times 10^{-7}$ & $<1.1 \times 10^{-7}$ & $<3.5 \times 10^{-14}$ \\
\hline
\end{tabular}

${ }^{a}$ Average binding potentials and average cocaine occupancy (in the caudate and putamen) for the non-vaccinated and dAd5GNE-vaccinated animals.

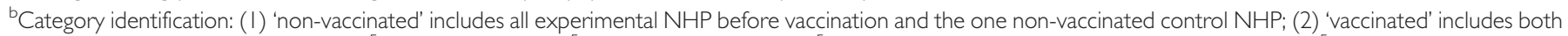
vaccinated NHPs with titers $<4 \times 10^{5}$ and titers $>4 \times 10^{5}$; and (3) 'titers $>4 \times 10^{5}$ ' includes only vaccinated $\mathrm{NHP}$ with titers $>4 \times 10^{5}$. 
a

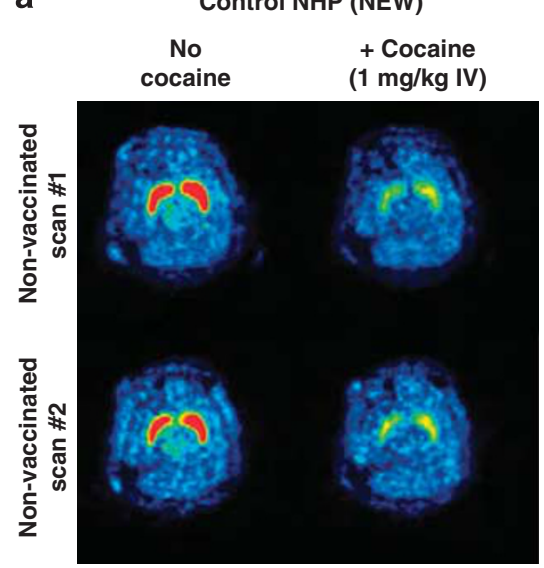

d

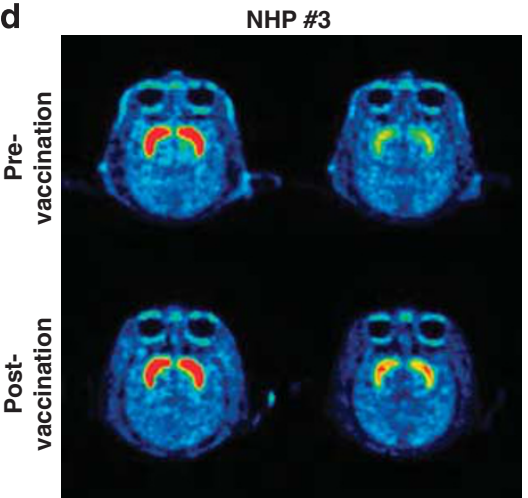

b

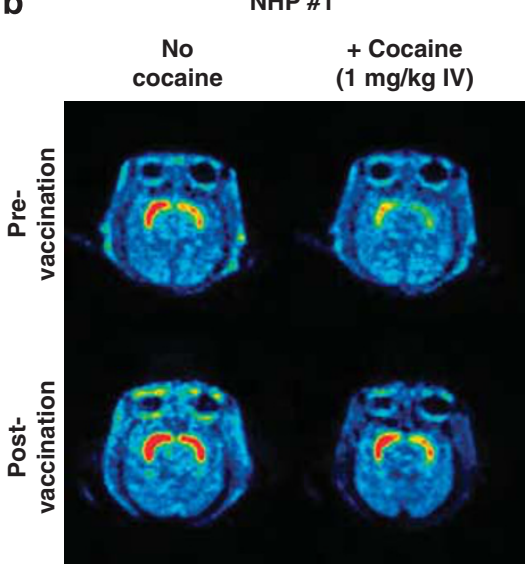

e

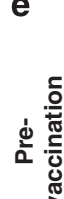

C

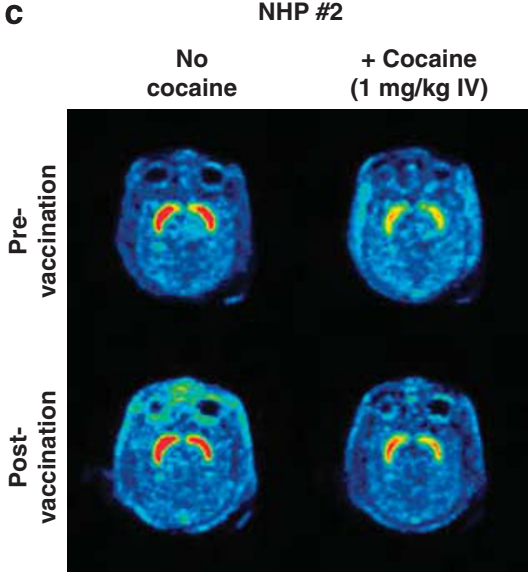

Color scale bar (SUV ratio)

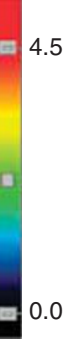

Figure 2 [ ' $\mathrm{C}$ C PE2I-PET images before and after dAd5GNE vaccination with and without cocaine administration. The images display the standard uptake value (SUV) of cortical and subcortical areas normalized to the SUV of the reference region, cerebellum. (a) Control, non-vaccinated. (b-e) Vaccinated, correspond to nonhuman primates (NHP) \#I-4. For each panel, top left-pre-vaccination without cocaine; top right-pre-vaccination with cocaine; bottom left-post-vaccination without cocaine; and bottom right-post-vaccination with cocaine. In all panels, the cocaine dose was I mg/kg. (f) The color scale bar representing the SUV ratio (scale 0.0-4.5) for all images.

non-vaccinated groups $(P=0.2$ and $P=0.4$ for the caudate and the putamen, respectively), and $\left[{ }^{11} \mathrm{C}\right]$ PE2I-DAT BPs in the absence of cocaine were consistent with previous reports of this tracer (Emond et al 2008; Halldin et al 2003).

The assessment of the BP of $\left[{ }^{11} \mathrm{C}\right] \mathrm{PE} 2 \mathrm{I}$ in the presence of cocaine, a binding competitor of DAT, showed a significant drop in the non-vaccinated NHP, with a large displacement of $\left[{ }^{11} \mathrm{C}\right]$ PE2I by cocaine. This resulted in a reduced BP in the caudate $(3.2 \pm 0.4, n=8)$ and putamen $(3.2 \pm 0.4, n=8)$ of naive NHP. However, unlike the naive controls (nonvaccinated and pre-vaccination), the dAd5GNE-vaccinated NHP showed only a slight reduction in BP of $\left[{ }^{11} \mathrm{C}\right]$ PE2I in the presence of cocaine. dAd5GNE vaccination resulted in high $\left[{ }^{11} \mathrm{C}\right] \mathrm{PE} 2 \mathrm{I}$ BPs in the caudate $(6.7 \pm 0.6, n=12$, Table 1$)$ and putamen $(6.9 \pm 0.6, n=12$, Table 1$)$, indicating minimal displacement by cocaine.

Calculation of the change in the $\left[{ }^{11} \mathrm{C}\right] \mathrm{PE} 2 \mathrm{I}$ BP in nonvaccinated animals showed a significantly large decrease in $\mathrm{BP}$ of the caudate $\left(\triangle \mathrm{BP}_{\mathrm{ND}}=5.2 \pm 0.4, P<10^{-5}, n=8\right)$ and putamen $\left(\triangle \mathrm{BP}_{\mathrm{ND}}=5.5 \pm 0.4, P<10^{-5}, n=8\right.$; Innis et al 2007). The change in $B P$ in dAd5GNE-vaccinated NHPs showed only a small displacement of PE2I by cocaine in the caudate $\left(\triangle \mathrm{BP}_{\mathrm{ND}}=2.8 \pm 0.6, P<10^{-2}, n=12\right)$ and in the putamen $\left(\Delta \mathrm{BP}_{\mathrm{ND}}=2.8 \pm 0.7, P<10^{-2}, n=12\right.$; Figure 2a right images, Figure $2 \mathrm{~b}-\mathrm{e}$ right images and Table 1 ).
The percent cocaine occupancy calculated from the change in BPs displayed in images (Figure 2) was 10.2, 16.0, 22.5, and $55.4 \%$ in the four vaccinated NHP, respectively (Figure 2b-e).

Assessment of the time-activity curve (during the 90-min PET scan) of $\left[{ }^{11} \mathrm{C}\right]$ PE2I uptake and binding demonstrated a vaccination-dependent reduction in the displacement of $\left[{ }^{11} \mathrm{C}\right] \mathrm{PE} 2 \mathrm{I}$ by cocaine in the caudate and putamen (Figure $3 \mathrm{~b}$ $v s$ Figure $3 \mathrm{~d}$ ). There was variability from animal to animal. As an example, in NHP \#3 at 21 weeks post vaccination, there was only a small decrease in $\left[{ }^{11} \mathrm{C}\right] \mathrm{PE} 2 \mathrm{I}$ binding following administration of cocaine, resulting in the calculated cocaine occupancy of only $22.5 \%$ (Figure $3 \mathrm{c} v \mathrm{~s}$ Figure 3d); in contrast, in NHP \#3 at 0 weeks, there was a large displacement of $\left[{ }^{11} \mathrm{C}\right]$ PE2I binding after cocaine administration, with a cocaine occupancy of $67.0 \%$ (Figure $3 \mathrm{a}$ and $\mathrm{b}$ ). The vaccinated animal showed reduced cocaine access to the DAT during the 90-min time course of the PET scan, the longest time point evaluated.

Comparison of studies before and after vaccination (pairwise repeated measures analysis) demonstrated a reduction in cocaine occupancy $(P<0.02, \mathrm{~F}=28.32)$. Cocaine occupancy in both the caudate and putamen correlated inversely with anti-cocaine antibody titers (Figure 4). Relevant to the cocaine occupancy of $47 \%$, 


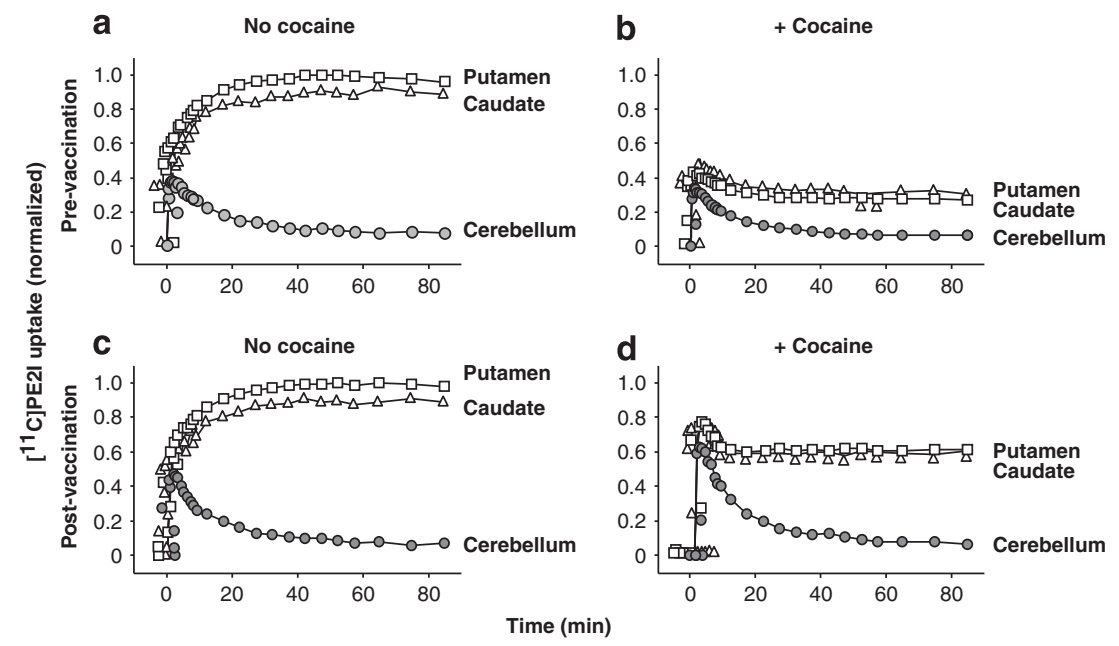

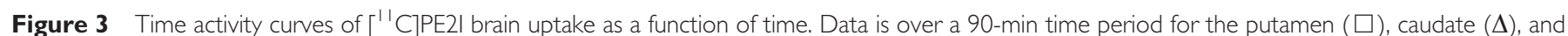
cerebellum ( ). The data is from nonhuman primate \#3, (a) pre-vaccination without cocaine; (b) pre-vaccination with cocaine; (c) post-vaccination without cocaine; and (d) post-vaccination with cocaine. In all panels with cocaine, cocaine administration was I mg/kg.

which represents the threshold associated with the subjective 'high' (Volkow et al 1997a), the pre-vaccinated NHP and the non-vaccinated control animal demonstrated cocaine occupancies at or above $47 \%$ following cocaine administration. However, vaccinated NHP with antibody titers $>4 \times 10^{5}$ invariably had cocaine occupancy $<20 \%$, significantly below $47 \%$ (Figure 4 ), indicating the capacity of dAd5GNE vaccine to limit cocaine occupancy below the threshold level. In non-vaccinated NHP, cocaine occupancy was $62.5 \pm 4.2 \%$. Post vaccination, when the anti-cocaine antibody titers were $<4 \times 10^{5}$, the reduction in cocaine occupancy, although significant $(P<0.03)$, was just $10 \%$. In contrast, in NHP with anti-cocaine antibody titers $\geqslant 4 \times 10^{5}$, the cocaine occupancy was only $15.6 \pm 2.5 \%$; this is a fourfold reduction in average cocaine occupancy $\left(P<10^{-6}\right.$; Figure $\left.4 \mathrm{~d}\right)$.

\section{DISCUSSION}

The addictive properties of cocaine result from the cocainemediated blockade of the DAT in the caudate and putamen, allowing dopamine to accumulate in the synaptic clefts (Haile et al 2012b; Howell and Kimmel 2008; Kahlig and Galli 2003; Koob and Volkow 2010). In humans, the perceived rewarding effect or 'high' from cocaine occurs when there is $>47 \%$ DAT occupancy by cocaine (Volkow et al 1997a). Thus, for an anti-cocaine vaccine to be successful, it must be able to prevent cocaine access to DAT below this threshold. Using PET imaging with $\left[{ }^{11} \mathrm{C}\right]$ PE2I DATspecific tracer, the data demonstrates that the dAd5GNE vaccine can effectively reduce cocaine DAT occupancy below this threshold to levels of $<20 \%$ in NHP with high titers consistent with the conclusion that dAd5GNE could be an effective vaccine for cocaine addiction.

Experimental animal and human studies using PET to evaluate cocaine occupancy of the DAT have substantiated the role of dopamine and cocaine DAT occupancy in the reward and addiction pathway circuitry of the basal ganglia (Gould et al 2012; Hanlon and Canterberry 2012; Koob and
Kreek 2007; Koob and Volkow 2010; Votaw et al 2002). The PET imaging radiotracer $\left[{ }^{11} \mathrm{C}\right]$ PE2I, which has high affinity and specificity for DAT, has optimized the assessment of cocaine binding to DAT (Halldin et al 2003; Emond et al 2008). The current study provides a novel approach of using this tracer as a tool to measure the efficacy of anti-cocaine therapy to reduce distribution of cocaine to the DAT, a technology that could be applied to human trials of anticocaine vaccine efficacy.

To date, most therapies in development to treat cocaine addiction have focused on a receptor agonist or antagonist mechanism to reduce the sensitivity to the pharmacological action of cocaine (Howell and Kimmel 2008; Jupp and Lawrence 2010; Kalivas 2007; Moeller et al 2012; Volkow et al 2009). Several drugs (eg, vigabatrin, tiagabine, modafinil, and disulfiram) showed promise in experimental animal studies, but clinical trials with these drugs have been inconclusive (Goudriaan et al 2013; Haile et al 2012a; Haile et al 2012b; National Institute on Drug Abuse 2010; Shorter and Kosten 2011). Because these pharmacotherapies attempt to reduce sensitivity in the brain to the pharmacological effect of cocaine, they mostly target pathways associated with cocaine addiction. Consequently, they may have downstream or secondary effects from the site of drug action, and may block other dopaminergic pathways (Best et al 2009; Zheng and Zhan 2012). In contrast, immunotherapies to treat cocaine addiction in the periphery are highly specific for the cocaine moiety and do not act on the brain signaling pathways, do not alter normal brain function and are thus less likely to evoke adverse effects (Czoty and Roberts 2012; Shorter and Kosten 2011; Zheng and Zhan 2012).

PET results for the high titer anti-cocaine dAd5GNEevoked immunity in the NHP demonstrated that the vaccine effectively sequestered administered cocaine in the blood and that repeat vaccine administrations were required to maintain an effective anti-cocaine antibody titer $(>4$ $\times 10^{5}$ ). After the initial three administrations of the vaccine, each animal received vaccine booster shots to assure high anti-cocaine titers before PET imaging. The intent was to 

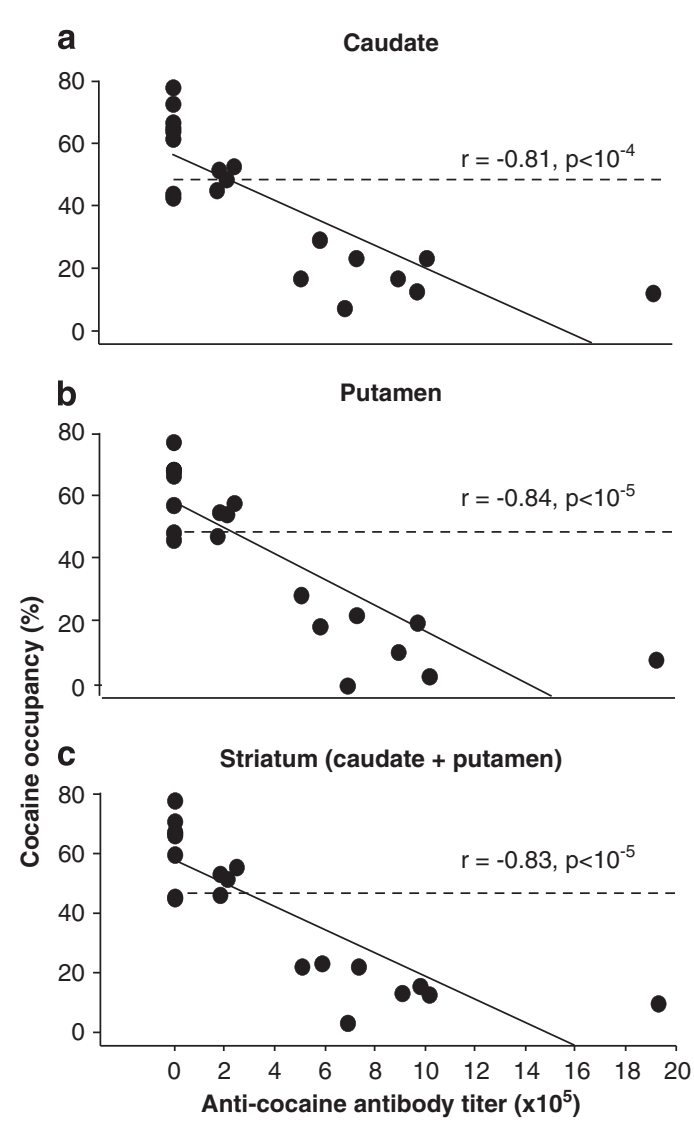

d Average \% occupancy in the striatum

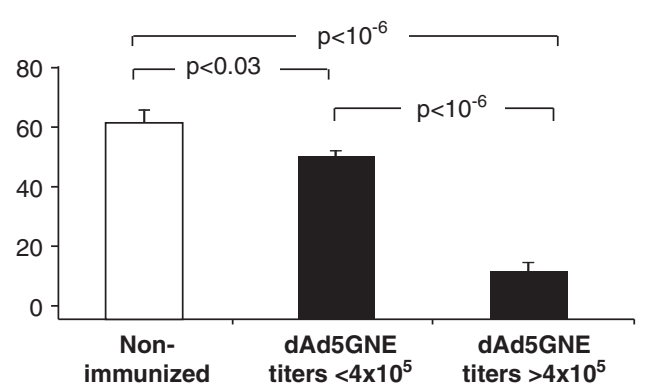

Figure 4 Correlation of cocaine occupancy and anti-cocaine antibody titer in dAd5GNE-vaccinated nonhuman primates before and after vaccination. The data from the non-vaccinated control is included. (a) Caudate; (b) putamen; and (c) striatum (caudate + putamen). Dashed line illustrates $47 \%$ cocaine occupancy. Pearson's coefficient displayed on each graph. (d) Average \% occupancy in the striatum for non-vaccinated and vaccinated nonhuman primates with anti-cocaine antibody titer $<4 \times 10^{5}$ and $>4 \times 10^{5}$. Shown is data derived from a total of 20 scans of the five nonhuman primates.

demonstrate proof-of-principle for vaccine efficacy. The range of antibody titers allowed determination of a threshold for efficacy in the context of a relatively high dosage of cocaine $(1 \mathrm{mg} / \mathrm{kg}$ intravenous), higher than that administered in human studies $(0.3-0.6 \mathrm{mg} / \mathrm{kg}$ intravenous; Haney et al 2010; Volkow et al 1997a). Interestingly, the best results with the TA-CD anti-cocaine vaccine (currently in clinical trials) were achieved only in individuals with the highest titers (Haney et al 2010). Here we found that titers above a threshold of $4 \times 10^{5}$ were effective at preventing cocaine access to the putamen and caudate DATs. The

dAD5GNE vaccine demonstrated efficacy with evoked titers above threshold in three of the four vaccinated NHP. As with most vaccines in which the breadth of coverage is typically $<100 \%$, a diverse genetic background is the likely factor for the low anti-cocaine titer $\left(\sim 2 \times 10^{5}\right)$ in one NHP in this study. Although not tested, an increase in vaccine dose may improve breadth of high-titer response. Rigorous evaluation of vaccine coverage would require a larger experimental group.

In the context that our laboratory and others have demonstrated excellent clinical safety profiles with infectious Ad vectors (Harvey et al 1999), it is expected that the use of a disrupted adenovirus will be relatively benign with respect to safety, particularly because dAd5GNE also lacks the ability to express any viral genes. While it is important to note that animals in this study received multiple dAd5GNE vaccinations and did not demonstrate systemic, site-of-injection, or behavioral adverse effects, extensive and formal evaluation of toxicology parameters will be necessary for vaccine development for human testing.

In this study, we show a novel approach using PET imaging to evaluate the efficacy of an anti-cocaine vaccine, dAd5GNE. This vaccine is based on the highly immunogenic capsid proteins of the human serotype 5 adenovirus, the stable cocaine hapten GNE, and the Adjuplex adjuvant. The data in the present study demonstrate that, in a NHP model, repetitive administration of the vaccine maintains high levels of anti-cocaine titers, sufficient to prevent systemically administered cocaine from binding to the DAT in the putamen and caudate at levels required to generate rewarding effects of cocaine in humans (Volkow et al 1997a).

\section{FUNDING AND DISCLOSURE}

These studies were supported, in part, by RC2 DA028847, R01 DA025305, and DA008590 to KDJ. MJH is supported, in part, by T32 HL094284. Shankar Vallabhajosula discloses consultation agreements with the following two radiopharmaceutical companies Molecular Insight Pharmaceuticals, Inc. and NCM-USA, Bronx, LLC. The remaining authors declare no conflict of interest.

\section{ACKNOWLEDGEMENTS}

We thank DN McCarthy and N Mohamed for help in preparing this manuscript, and RJ Ricart Arbona, Research Animal Resource Center, for help with the study. The authors thank the National Institute on Drug Abuse (NIDA) drug supply program for the cocaine used in this study and Advanced BioAdjuvants, LLC (Omaha, NE) for the Adjuplex used in this study.

\section{REFERENCES}

Anderson BB, Chen G, Gutman DA, Ewing AG (1998). Dopamine levels of two classes of vesicles are differentially depleted by amphetamine. Brain Res 788: 294-301.

Best JA, Nijhout HF, Reed MC (2009). Homeostatic mechanisms in dopamine synthesis and release: a mathematical model. Theor Biol Med Model 6: 21. 
Brimijoin S, Orson F, Kosten TR, Kinsey B, Shen XY, White SJ et al (2013). Anti-cocaine antibody and butyrylcholinesterase-derived cocaine hydrolase exert cooperative effects on cocaine pharmacokinetics and cocaine-induced locomotor activity in mice. Chem Biol Interact 203: 212-216.

Carroll ME, Zlebnik NE, Anker JJ, Kosten TR, Orson FM, Shen X et al (2012). Combined cocaine hydrolase gene transfer and anticocaine vaccine synergistically block cocaine-induced locomotion. PLoS One 7: e43536.

Ciliax BJ, Drash GW, Staley JK, Haber S, Mobley CJ, Miller GW et al (1999). Immunocytochemical localization of the dopamine transporter in human brain. J Comp Neurol 409: 38-56.

Czoty PW, Roberts DC (2012). Thinking outside the synapse: pharmacokinetic-based medications for cocaine addiction. Neuropsychopharmacology 37: 1079-1080.

DiChiara G, Bassareo V, Fenu S, De Luca MA, Spina L, Cadoni C et al (2004). Dopamine and drug addiction: the nucleus accumbens shell connection. Neuropharmacology 47(Suppl 1): 227-241.

Dolle F, Bottlaender M, Demphel S, Emond P, Fuseau C, Coulon C et al (2000). Highly efficient synthesis of [11C]PE2I, a selective radioligand for the quantification of the dopamine transporter using PET. J Labelled Cpd Radiopharm 43: 997-1004.

Emond P, Guilloteau D, Chalon S (2008). PE2I: a radiopharmaceutical for in vivo exploration of the dopamine transporter. CNS Neurosci Ther 14: 47-64.

Goudriaan AE, Veltman DJ, van den BW, Dom G, Schmaal L (2013). Neurophysiological effects of modafinil on cue-exposure in cocaine dependence: A randomized placebo-controlled cross-over study using pharmacological fMRI. Addict Behav 38: 1509-1517.

Gould RW, Porrino LJ, Nader MA (2012). Nonhuman primate models of addiction and PET imaging: dopamine system dysregulation. Curr Top Behav Neurosci 11: 25-44.

Haile CN, De La Garza R II, Mahoney JJ III, Nielsen DA, Kosten TR, Newton TF (2012a). The impact of disulfiram treatment on the reinforcing effects of cocaine: a randomized clinical trial. PLoS One 7: e47702.

Haile CN, Mahoney JJ III, Newton TF, De La Garza R II (2012b). Pharmacotherapeutics directed at deficiencies associated with cocaine dependence: focus on dopamine, norepinephrine and glutamate. Pharmacol Ther 134: 260-277.

Halldin C, Erixon-Lindroth N, Pauli S, Chou YH, Okubo Y, Karlsson $\mathrm{P}$ et al (2003). [(11)C]PE2I: a highly selective radioligand for PET examination of the dopamine transporter in monkey and human brain. Eur J Nucl Med Mol Imaging 30: $1220-1230$.

Haney M, Gunderson EW, Jiang H, Collins ED, Foltin RW (2010). Cocaine-specific antibodies blunt the subjective effects of smoked cocaine in humans. Biol Psychiatry 67: 59-65.

Hanlon CA, Canterberry M (2012). The use of brain imaging to elucidate neural circuit changes in cocaine addiction. Subst Abuse Rehabil 3: 115-128.

Harvey BG, Hackett NR, El-Sawy T, Rosengart TK, Hirschowitz EA, Lieberman MD et al (1999). Variability of human systemic humoral immune responses to adenovirus gene transfer vectors administered to different organs. J Virol 73: 6729-6742.

Herodin F, Thullier P, Garin D, Drouet M (2005). Nonhuman primates are relevant models for research in hematology, immunology and virology. Eur Cytokine Netw 16: 104-116.

Hicks MJ, De BP, Rosenberg JB, Davidson JT, Moreno AY, Janda KD et al (2011). Cocaine analog coupled to disrupted adenovirus: a vaccine strategy to evoke high-titer immunity against addictive drugs. Mol Ther 19: 612-619.

Howell LL, Kimmel HL (2008). Monoamine transporters and psychostimulant addiction. Biochem Pharmacol 75: 196-217.
Hume SP, Myers R, Bloomfield PM, Opacka-Juffry J, Cremer JE, Ahier RG et al (1992). Quantitation of carbon-11-labeled raclopride in rat striatum using positron emission tomography. Synapse 12: 47-54.

Innis RB, Cunningham VJ, Delforge J, Fujita M, Gjedde A, Gunn RN et al (2007). Consensus nomenclature for in vivo imaging of reversibly binding radioligands. J Cereb Blood Flow Metab 27: 1533-1539.

Jupp B, Lawrence AJ (2010). New horizons for therapeutics in drug and alcohol abuse. Pharmacol Ther 125: 138-168.

Kahlig KM, Galli A (2003). Regulation of dopamine transporter function and plasma membrane expression by dopamine, amphetamine, and cocaine. Eur J Pharmacol 479: 153-158.

Kalivas PW (2007). Neurobiology of cocaine addiction: implications for new pharmacotherapy. Am J Addict 16: 71-78.

Koob G, Hicks MJ, Wee S, Rosenberg JB, De BP, Kaminsky SM et al (2011). Anti-cocaine vaccine based on coupling a cocaine analog to a disrupted adenovirus. CNS Neurol Disord Drug Targets 10: 899-904.

Koob G, Kreek MJ (2007). Stress, dysregulation of drug reward pathways, and the transition to drug dependence. $A m \mathrm{~J}$ Psychiatry 164: 1149-1159.

Koob GF, Volkow ND (2010). Neurocircuitry of addiction. Neuropsychopharmacology 35: 217-238.

Lammertsma AA, Bench CJ, Hume SP, Osman S, Gunn K, Brooks DJ et al (1996). Comparison of methods for analysis of clinical [11C]raclopride studies. J Cereb Blood Flow Metab 16: 42-52.

Lindsey KP, Wilcox KM, Votaw JR, Goodman MM, Plisson C, Carroll FI et al (2004). Effects of dopamine transporter inhibitors on cocaine self-administration in rhesus monkeys: relationship to transporter occupancy determined by positron emission tomography neuroimaging. J Pharmacol Exp Ther 309: 959-969.

Martell BA, Orson FM, Poling J, Mitchell E, Rossen RD, Gardner T et al (2009). Cocaine vaccine for the treatment of cocaine dependence in methadone-maintained patients: a randomized, double-blind, placebo-controlled efficacy trial. Arch Gen Psychiatry 66: 1116-1123.

Moeller SJ, Honorio J, Tomasi D, Parvaz MA, Woicik PA, Volkow ND et al (2012). Methylphenidate enhances executive function and optimizes prefrontal function in both health and cocaine addiction. Cereb Cortex (doi:10.1093/cercor/bhs345); e-pub ahead of print.

Nader MA, Czoty PW (2005). PET imaging of dopamine D2 receptors in monkey models of cocaine abuse: genetic predisposition versus environmental modulation. Am J Psychiatry 162: 1473-1482.

Nader MA, Czoty PW (2008). Brain imaging in nonhuman primates: insights into drug addiction. ILAR J 49: 89-102.

National Institute on Drug Abuse (2010). Cocaine: Abuse and Addiction. National Institute on Drug Abuse.

Norman AB, Tabet MR, Norman MK, Buesing WR, Pesce AJ, Ball WJ (2007). A chimeric human/murine anticocaine monoclonal antibody inhibits the distribution of cocaine to the brain in mice. J Pharmacol Exp Ther 320: 145-153.

Ramakrishnan M, ves De MF, Kinsey BM, Ladbury JE, Kosten TR, Orson FM (2012). Probing cocaine-antibody interactions in buffer and human serum. PLoS One 7: e40518.

Rosenberg JB, Hicks MJ, De BP, Pagovich O, Frenk E, Janda KD et al (2012). AAVrh.10-mediated expression of an anticocaine antibody mediates persistent passive immunization that suppresses cocaine-induced behavior. Hum Gene Ther 23: 451-459.

Rosenfeld MA, Yoshimura K, Trapnell BC, Yoneyama K, Rosenthal $\mathrm{ER}$, Dalemans W et al (1992). In vivo transfer of the human cystic fibrosis transmembrane conductance regulator gene to the airway epithelium. Cell 68: 143-155.

Sasaki T, Ito H, Kimura Y, Arakawa R, Takano H, Seki C et al (2012). Quantification of dopamine transporter in human brain using PET with 18F-FE-PE2I. J Nucl Med 53: 1065-1073. 


\section{Cocaine vaccine prevents cocaine CNS binding}

A Maoz et al

Seki C, Ito H, Ichimiya T, Arakawa R, Ikoma Y, Shidahara M et al (2010). Quantitative analysis of dopamine transporters in human brain using [11C]PE2I and positron emission tomography: evaluation of reference tissue models. Ann Nucl Med 24: 249-260.

Shen XY, Orson FM, Kosten TR (2012). Vaccines against drug abuse. Clin Pharmacol Ther 91: 60-70.

Shetty HU, Zoghbi SS, Liow JS, Ichise M, Hong J, Musachio JL et al (2007). Identification and regional distribution in rat brain of radiometabolites of the dopamine transporter PET radioligand [11C]PE2I. Eur J Nucl Med Mol Imaging 34: 667-678.

Shorter D, Kosten TR (2011). Novel pharmacotherapeutic treatments for cocaine addiction. BMC Med 9: 119.

Substance Abuse and Mental Health Services Administration (2012). Results from the 2011 National Survey on Drug Use and Health: Summary of National Findings, NSDUH Series H-44, HHS Publication No. (SMA) 12-4713. Rockville, MD: Substance Abuse and Mental Health Services Administration. http:// www.samhsa.gov/data/nsduh/2k11 results/nsduhresults2011.pdf.

Treweek JB, Janda KD (2012). An antidote for acute cocaine toxicity. Mol Pharm 9: 969-978.

Volkow ND, Fowler JS, Logan J, Alexoff D, Zhu W, Telang F et al (2009). Effects of modafinil on dopamine and dopamine transporters in the male human brain: clinical implications. JAMA 301: 1148-1154.

Volkow ND, Wang GJ, Fischman MW, Foltin RW, Fowler JS, Abumrad NN et al (1997a). Relationship between subjective effects of cocaine and dopamine transporter occupancy. Nature 386: 827-830.

Volkow ND, Wang GJ, Fowler JS, Logan J, Gatley SJ, Hitzemann R et al (1997b). Decreased striatal dopaminergic responsiveness in detoxified cocaine-dependent subjects. Nature 386: 830-833.

Votaw JR, Howell LL, Martarello L, Hoffman JM, Kilts CD, Lindsey $\mathrm{KP}$ et al (2002). Measurement of dopamine transporter occupancy for multiple injections of cocaine using a single injection of [F-18]FECNT. Synapse 44: 203-210.

Ward KW, Smith BR (2004). A comprehensive quantitative and qualitative evaluation of extrapolation of intravenous pharmacokinetic parameters from rat, dog, and monkey to humans. I. Clearance. Drug Metab Dispos 32: 603-611.

Wee S, Hicks MJ, De BP, Rosenberg JB, Moreno AY, Kaminsky SM et al (2012). Novel cocaine vaccine linked to a disrupted adenovirus gene transfer vector blocks cocaine psychostimulant and reinforcing effects. Neuropsychopharmacology 37: 1083-1091.

Wilcox KM, Lindsey KP, Votaw JR, Goodman MM, Martarello L, Carroll FI et al (2002). Self-administration of cocaine and the cocaine analog RTI-113: relationship to dopamine transporter occupancy determined by PET neuroimaging in rhesus monkeys. Synapse 43: 78-85.

Zheng F, Zhan CG (2012). Are pharmacokinetic approaches feasible for treatment of cocaine addiction and overdose? Future Med Chem 4: 125-128.

Supplementary Information accompanies the paper on the Neuropsychopharmacology website (http://www.nature.com/npp) 